Original Research Paper

\title{
Missouri Spring Freeze Event and Crop Loss Analysis for the Years 1982-2015
}

\author{
${ }^{1}$ Mirza Mohd Shahriar Maswood, ${ }^{4}$ Ali Koleiny, ${ }^{1}$ Scott Nickell, ${ }^{2}$ Laura Wymer, \\ ${ }^{3}$ Ronald Morris, ${ }^{3}$ Majid Bani-Yaghoub and ${ }^{4}$ Jimmy Adegoke \\ ${ }^{I}$ School of Computing and Engineering, Department of Computer Science and Electrical Engineering, \\ University of Missouri - Kansas City, 5110 Rockhill Road, Kansas City, MO 64110, Missouri, USA \\ ${ }^{2}$ School of Biological Sciences, University of Missouri-Kansas City, 5007 Rockhill Road, \\ Kansas City, Missouri 64110, Missouri, USA \\ ${ }^{3}$ Department of Mathematics and Statistics, University of Missouri-Kansas City, \\ 5100 Rockhill Road, Kansas City, MO 64110, Missouri, USA \\ ${ }^{4}$ Department of Geosciences, University of Missouri-Kansas City, 5110 Rockhill Road, \\ Kanas City, Missouri 64110, Missouri, USA
}

Article history

Received: 14-12-2017

Revised: 23-03-2018

Accepted: 18-04-2018

Corresponding Author:

Mirza Mohd Shahriar Maswood

School of Computing and

Engineering, Department of

Computer Science and

Electrical Engineering,

University of Missouri -

Kansas City, 5110 Rockhill

Road, Kansas City, MO 64110,

Missouri, USA

Email: mmnt7@mail.umkc.edu

\begin{abstract}
A spring freeze is an unexpected freeze event occurring in late spring that can result in severe domestic crop loss. These events coincide with seasonal weather conditions that promote early crop development. As a consequence, early growth is most susceptible to freeze damage. Spring temperature fluctuations pose significant threat to crop yield and growth, when compared to onsistently cold springtime temperatures. In this study, a thirty-four-year span (1982 to 2015) of historical climate, agricultural and crop insurance data for Missouri was analyzed. Risk analysis was performed for each Missouri county to determine statistical relationships between crop loss and springtime warm-cold temperature fluctuations. Statewide, several regions were identified as having an increased susceptibility to freeze events, with Lafayette County emerging as the state's leading county in agricultural losses due to freeze events. The window for peak freeze damage for Lafayette County was identified as the last week of March through the first week of April. The years 1985, 1996 and 2007 stood apart in the dataset as they correspond to the highest crop damages on record. Each of these years also corresponds to a doubling of severity in the reported crop losses.
\end{abstract}

Keywords: Spring Freeze, Crop Loss Analysis, Advective and Radiational Freeze, Plant's Structure, Winter-Hardiness

\section{Introduction}

Late spring freezes are a devastating climate phenomenon because they strike a crop during its most vulnerable growth cycle (Gu et al., 2008). The period of seasonal time for spring freeze events is identified as late March through the first half of April. Some plant varieties are capable of internal composition adjustments to improve survivability rates in freezing temperatures. However, this mechanism alone is not efficient enough to protect crops from damage caused by a freeze event's sudden and drastic temperature fluctuations. Spring freeze events may require replanting affected crops in order to attain acceptable harvest yields. In addition to replanting affected crops, freeze events have large extenuating implications beyond Missouri. Affected crop yields in the state reach beyond regional economics and impact national sectors, including market prices and food security.

In total, between1982-2015 seven major freeze events resulted in domestic losses totaling over a billion United States Dollars (USD). According to the National Centers for Environmental Information (NCEI), a subset of the National Oceanic and Atmospheric Administration (NOAA), these seven freeze events occurred respectively in 1983, 1985, 1989, 1990, 1998 and 2007 (twice). Reduced crop yields associated with freeze events are visible in national Gross Domestic Product (GDP). The time of occurrence and amount of loss due to these seven freeze events are presented in Table 1. 
Table 1: Seven major U.S. freeze events since 1983; each exceeding 1.5 billion dollars in domestic crop loss. (NOAANCEI, 2017)

\begin{tabular}{llll}
\hline Date & Loss (USD billions) & States affected & Damaged plants \\
\hline April 4, 2007, to & $\$ 2.4$ & Mostly Alabama, Arkansas, Georgia, & Fruit crops and field crops
\end{tabular}

April 10, 2007

Illinois, Indiana, Iowa, Kansas, Kentucky,

(especially wheat)

Mississippi, Missouri, Nebraska, North

Carolina, Ohio, Oklahoma, South Carolina,

January 11,2007 , to

January 17,2007

December 20, 1998, to

December 28, 1998

December 18, 1990, to

December 25, 1990

December 23, 1989, to

December 25, 1989

January 20, 1985, to

January 22, 1985

December 15, 1983, to

December 25, 1983
\$1.6 California

\$3.7 Majorly the Central and Southern San Joaquin Valley of California

Majorly the Central and Southern San

Joaquin Valley of California

Central and northern Florida

Central and northern Florida

Central and northern Florida
Numerous agricultural crops such as citrus, berry and vegetables

Different fruits and vegetables

Mainly citrus and avocado trees

Citrus crops

Mostly citrus crops

Citrus crops
Few places in the US escape freezing temperatures. The January 2007 freeze event dropped temperatures into negative double digit temperatures (Celsius) for central California and into the negative single digit temperatures as far south as the Mexican border with agricultural losses estimated at $\$ 1.4$ billion. Three months later, during the April 2007 freeze, eighteen states were seriously affected with hard hit crops such as winter wheat in the Plains and emerged corn and fruit trees in the Southeast. Plants in an advanced stage of development sustain severe frost damage to buds, flowers and sprouts (Brotak, 2014). This freeze, termed the 2007 Easter Freeze, occurred after an unseasonably warm March prompted early crop growth. The Easter Freeze of 2007 was devastating since warm March temperatures were succeeded by a dual combination of an advective freeze and a radiational freeze event. Most commonly, a freeze event is either advective or radiational, not typically a combination of both freeze types. Advective freezing occurs when cold air is blown into an area and low temperatures are maintained by cloud coverage. A radiational freeze, by comparison, occurs when there is low humidity and no cloud cover, thus allowing ground warmth to quickly escape upwards into the atmosphere throughout the night (Warmund et al., 2008).

Springtime freeze events have the capacity to affect a wide range of domestic crops from cereal grains (e.g., wheat and barley), to berries and nuts, to vegetables and fruit trees. Lack of winter hardiness and a susceptibility to spring frost are identified as two of the most significant problems for current blueberry cultivars (Ehlenfeldt et al., 2012). According to an Oct. 2nd, 2014 news release from the Missouri Department of Agriculture (MDA) 88 more than \$450, 000 in federal funding through the United States Department of Agriculture's (USDA) Specialty Crop Block Grant program was allotted to educate both consumers and producers on Missouri specialty crops such as berries. The grant included plant protection as well as, large and small-scale production initiatives (MDA, 2014).

In 2012 the USDA developed a new Plant Hardiness Zone Map for the United States. This map determines where certain species are expected to thrive. The 2012 edition revealed two new zones and location shifts where many zone borders moved north (Daly et al., 2012). As zones move north, less winter hardy varietals may be introduced and thrive. However, these varietals are susceptible to spring freeze events as many lack the genetic adaptations of low rated winter hardy plants. Cold hardy varieties possess a genetic expression that allows them to acclimate to freezing temperatures and essentially survive varying degrees of freezing temperatures. When considering how freezing temperatures impact plants and their effect upon agricultural crops, it's important to understand water within a plant's structure. Plant tissue consists of approximately $85 \%$ water. When water molecules freeze, they form rigid hexagonal arrangements in an orderly lattice pattern (Taiz and Zeiger, 2007). This crystalline formation not only changes the rigidity of the water molecule but also increases its spatial volume by $9 \%$. Thus, temperatures reaching $0^{\circ} \mathrm{C}$ or below result in cell tissue expansion. This expansion ruptures the plant's organelles and cell walls resulting in acute damage or whole plant death.

As a plant trait, cold hardiness is both a product of environmental conditions and an expression of genetic capability. To address falling temperatures and daylight these varietals trigger an increased density of solutes into the water portion of the cells. This solution freezes at a lower temperature than pure water and protects plant tissue from cell ruptures during freezing. During this process, cell walls also gradually become more durable 
by changing the arrangement of lipids ( $\mathrm{Li}$ and Sakai, 1982). Cold hardiness is summarized as the ability to avoid ice crystal formation within or between cells. If ice crystals form, they rupture cell walls. As a result, a plant loses life sustaining vital substances. A plant's cold hardiness rating is given by survivability at a determined lowest lethal temperature. A low hardiness rating does not mean a plant is protected from freeze events (Regan, 2012). Freeze events are damaging because a plant's physiology is an environmental interaction that occurs with seasonality.

Cold hardiness consists of three process stages: (i) Acclimation, (ii) winter hardiness and (iii) deacclimation. Acclimation is triggered by warm days and decreasing daylight hours and usually begins in the months of August through September. Acclimation is a process that moves water out of cells and assists in compound development to lower the freeze point of water between cell walls. Mid-winter hardiness is the level often used to designate a plant's cold hardiness rating (Regan, 2012). Generally, this is a period of dormancy when the plant is gradually able to withstand various low temperatures determined by the plant's genes and current environmental adaptations. During the month of January, most plants reach their full winter hardy potential. De-acclimation is triggered by warming temperatures and increased daylight hours during March and April (Li and Sakai, 1982). De-acclimation allows for spring growth. Therefore, it is important to note springtime cold-warm temperature fluctuations. For shoots, the de-acclimation process is irreversible (Regan, 2012). Once a plant enters deacclimation, it no longer has the ability to revert to winter-hardy until the full seasonal cycle has been completed. Furthermore, deacclimated plants that do survive a freeze event may produce a smaller yield during harvest. Reduced plant yield is a result of the cold temperatures interacting with sensitive plant hormones during the plant's sprouting phase. This sprouting phase is responsible for determining yield potential (Striegler et al., 2007). Deacclimation of a plant can be completed in as little as 2 to 3 days.

The cold hardiness cycle is expressed differently in varying components of a plant's structure. Structures such as buds, leaves, stems, root collar and roots all have different hardiness ratings. These plant structures also develop their winter hardiness at differing rates. Certain components of the plant's structure are more vulnerable to freezing temperatures than others. For instance, flower buds are the least hardy, often followed by vegetative buds and stems (Regan, 2012). De-acclimation windows are integral to flower bud survival and thus directly related to yield potential (Ehlenfeldt et al., 2012). The plant stage of development at time of exposure to freezing temperatures determines the type of loss or damage that will be incurred. Cold hardy varieties can adapt in warmer climates resulting in the loss of their ability to adjust to more severe temperatures, despite inherent genetic capabilities. If a cold hardy variety experiences an unseasonably warm winter it will not express the same proper acclimation ability in withstanding freezing temperatures and in the event of a subsequent freeze, the plant will not withstand damage (Burke et al., 1976). In the event of a sudden temperature drop after an unusually warm winter, such as the Easter Freeze event of 2007, each plant will have already undergone deacclimation. Consequently, water inside of the plant cells freezes and ruptures both the cell wall and organelles as it expands. Whole crops can be destroyed due to these extreme or unseasonable freezing events (McMechan and Elmore, 2016). The Easter freeze sparked discussion about how agriculture may better adjust to survive potentially similar climate events.

Several techniques can be used to mitigate freeze damage to plants and crops. One of the most successful methods of protecting plants from cold injury has been white copoly coverage during freeze events (Regan, 2012). However, this method is labor-intensive. Other mitigation methods include fan use to circulate warm air onto a field, or crop coverings may be used when plants are small enough to accommodate such structures (Snyder, 2000). Somewhat counterintuitively, water sprayed on the outside of the plant, with its high thermal capacity, can help insulate the interior of the plant from the freezing temperature in the case of a light freeze. Furthermore, a growing industry for genetically modified organisms (GMO's) pioneered by companies such as Monsanto, work to create newer plant strains with enhanced survivability under freezing temperatures (Monsanto, 2017).

This study examines the 2007 Easter Freeze alongside other annual warm-cold spring temperature fluctuation patterns that resulted in substantial crop loss, in an effort to better understand the impact of spring freezes for Missouri crops. Missouri crop loss data and the corresponding insurance claims from spring freeze events are then compared annually from 1982 through 2015. Analysis of climate and crop loss data seeks to substantiate the hypothesis that if early warm spring temperatures are succeeded by one or more freeze events, this type of freeze is most agriculturally damaging. This research aims to improve identification, understanding and mitigation of future spring freeze events in Missouri and their associated impact. Utilizing spatio- temporal crop loss and climate data, we examine freeze trends, seasonality, characteristics and look for any periodicity within Missouri's annual records. Better understanding of past spring freeze events can serve to inform farming communities, policy makers and reduce economic loss both in the Midwest region and nationally. The specific objectives of this research include the following: 
i. Examine annual records for historical climate and agricultural loss data from 1982 through 2015 for each Missouri county

ii. Analyze daily climate datasets for springtime warmcold temperature fluctuations associated with historical spring freeze events

iii. Provide an overview of Missouri's most significant spring freeze years during the thirtyfour-year study period

iv. Determine if the patterns of warm-cold temperature fluctuations influence the severity of crop loss due to freeze events

v. Identify the State's top risk counties for agricultural losses due to springtime freeze and identification of Missouri's most vulnerable freeze regions

\section{Materials and Methods}

\section{Missouri Climate and Crop Loss Data}

Daily minimum temperature data from January 1, 1982 to July 31, 2014 for Lafayette County was obtained and analyzed from the National Centers for Environmental Prediction-Climate Forecast System Reanalysis (NCEP-CFSR) (Saha and Coauthors, 2010). Crop loss data was collected directly from the United States Department of Agriculture Risk Management Agency (USDA-RMA, 2016), which contains the following categories for each Missouri county; insurance company payout for various crop loss, including cause of crop loss and the indemnity loss. The indemnity loss amount was then converted to reflect a loss total according to its corresponding 2016 USD amount. For instance, the deflator index for 1980 is 44.377 and for 2016 it is 111.188 (Implicit Price Deflators 2008). It follows that 1.00 USD of 1980 is worth 2.51 USD of 2016 , with numbers rounded to two decimal places.

\section{Spatial and Temporal Data Analysis}

Spatial and temporal data analysis employed in this study follows earlier work by Ozaki et al. (2008) which used hierarchical Bayesian models to jointly model the temporal and spatial autocorrelation to predict the crop insurance premium rates. Spatio-temporal analysis was also used in several recent studies, including the study of crop damage due to climate change (Laforge et al., 2017) and forest loss due to cocaine trafficking (Sesnie et al., 2017). Our model for conducting spatial and temporal data analysis is explained as follows:

Let the annual percentile loss due to freeze and the annual crop loss due to freeze in a particular year in USD be $\mathrm{x}$ and $\mathrm{y}$ respectively. Moreover, the total amount of crop loss due to freeze over the 34 years (1982-2015) in USD is denoted using z. Equation (1) corresponds to Fig. 1a and $1 \mathrm{~b}$ :

$$
x=100 y / z
$$

Next, Equation (2) is used to determine Missouri's top five counties from 1982-2015 with the highest crop loss due to a freeze event:

$A=100 \sigma / \tau$

A is the annual percentile loss due to freeze in the top five counties, $\sigma$ is the sum of annual crop loss in the top five counties due to freeze in USD and $\tau$ is the total amount of crop loss due to freeze in that year in corresponding USD amount. This formula is used to generate Fig. 2, which represents an annual percent loss for Missouri's top five counties. It can be seen that the top five counties constitute a substantial amount of loss in Missouri during 1985-1997, 2000, 2002 and 2005-2010 and 2015. Although Missouri's top loss counties vary annually in as seen in Table 3 for the thirty-four-year span of 1982 through 2015, certain counties emerged with substantially more annual occurrences. Figure 4 represents the percentile crop loss due to freeze in Lafayette County, Missouri, from 1982-2015. The following Equation (3) was used to generate this figure:

$A_{L}=100 C / \epsilon$

$A_{L}$ is Annual percentile loss due to freeze in Lafayette County, $\mathrm{C}$ is the crop loss due to freeze in USD and $\in$ is the total amount of crop loss in that year in USD. Please note, all analyses were conducted using USDA-RMA sourced Missouri crop loss data.

\section{Results}

\section{Temporal Crop Loss Data Analysis}

Figure 1a, 1b and Table 2, analysis revealed the most significant freeze events occurred in the years of 1985 , 1992, 1995, 1996, 2000 and 2007, which result in total crop loss figures of 2.02, 1.04, 1.37, 5.06, 2.65 and 10.4 million dollars respectively. These loss amounts are reported through insurance company pay outs. When examining Missouri, we found that there were several significantly more damaging freezes, as well as, many years with little or no freeze loss.

Furthermore, the periodicity of 1985, 1996 and 2007 stand out in the 34-year data set span. In Fig. 1a and 1b please note the severity of 2007 freeze losses in comparison with the other event losses. Table 2 denotes an interesting pattern emergence in which each of these years corresponds to nearly doubling of loss severity for that freeze event. 
Mirza Mohd Shahriar Maswood et al. / American Journal of Agricultural and Biological Sciences 2018, Volume 13: 16.27 DOI: 10.3844/ajabssp.2018.16.27

Table 2: Missouri's most significant years of freeze damage losses (1982-2015)

\begin{tabular}{lllllll}
\hline Year & 1985 & 1992 & 1995 & 1996 & 2000 & 2007 \\
\hline Crop loss (USD/Millions) & 2.02 & 1.04 & 1.37 & 5.06 & 2.65 & 10.4 \\
\hline
\end{tabular}

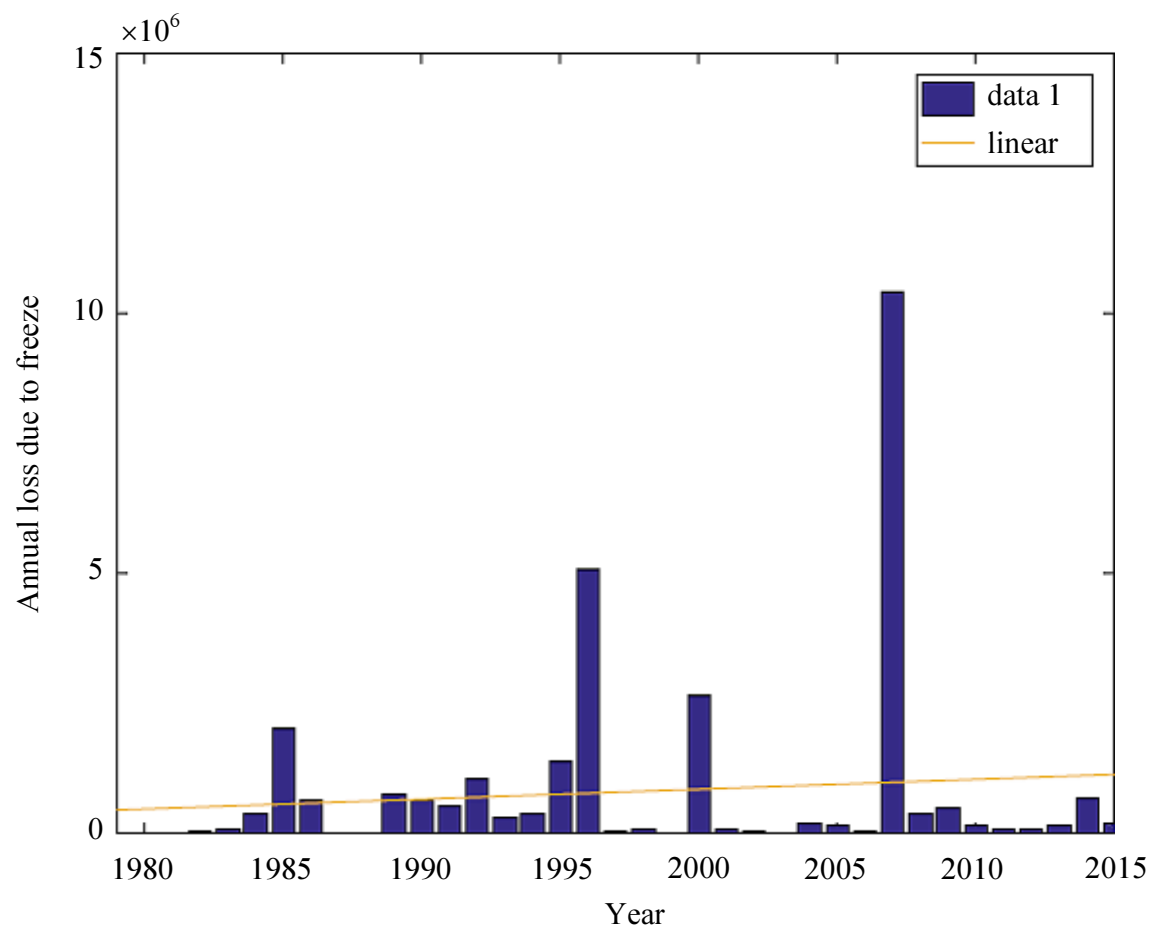

(a)

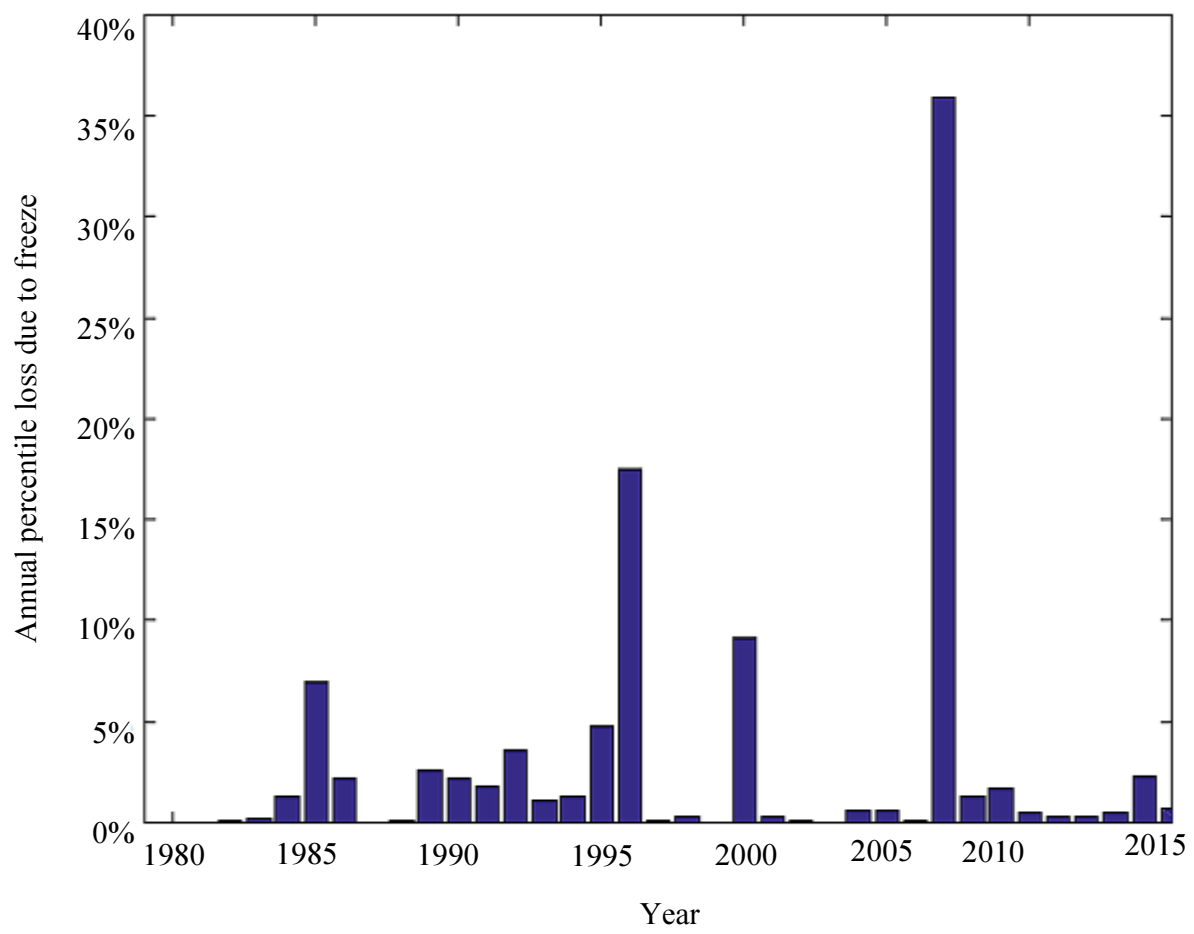

(b)

Fig. 1: Crop loss in Missouri due to spring freeze (a) Annual loss in dollars due to freeze from 1979 to 2015; the solid line represents the regression line fitted to the data (b) annual percentile loss due to freeze for each year from 1979 to 2015 
Table 3, illustrates the top five Missouri Counties with highest crop loss amounts due to freeze from 1982 to 2015. The top five counties are Dunklin, Barton, Lafayette, Vernon and Audrain. These counties are affected more frequently when compared to other counties for $13,12,18,12$ and 13 years respectively during the thirty-four-year span. For each of the counties, maximum freeze loss years are indicated alongside that year's reported agricultural losses.
When examining the number of counties affected by the freeze in a particular year, little correlation to the total loss figures was found. However, extreme event years, such as 2007 have the largest number of affected counties but more moderate years range from large swaths of affected counties to a small pinpointed section of Missouri. Figure 2 represents percent crop loss due to freeze in Missouri's top five counties. In certain years the percent crop loss due to freeze exceeds $50 \%$.

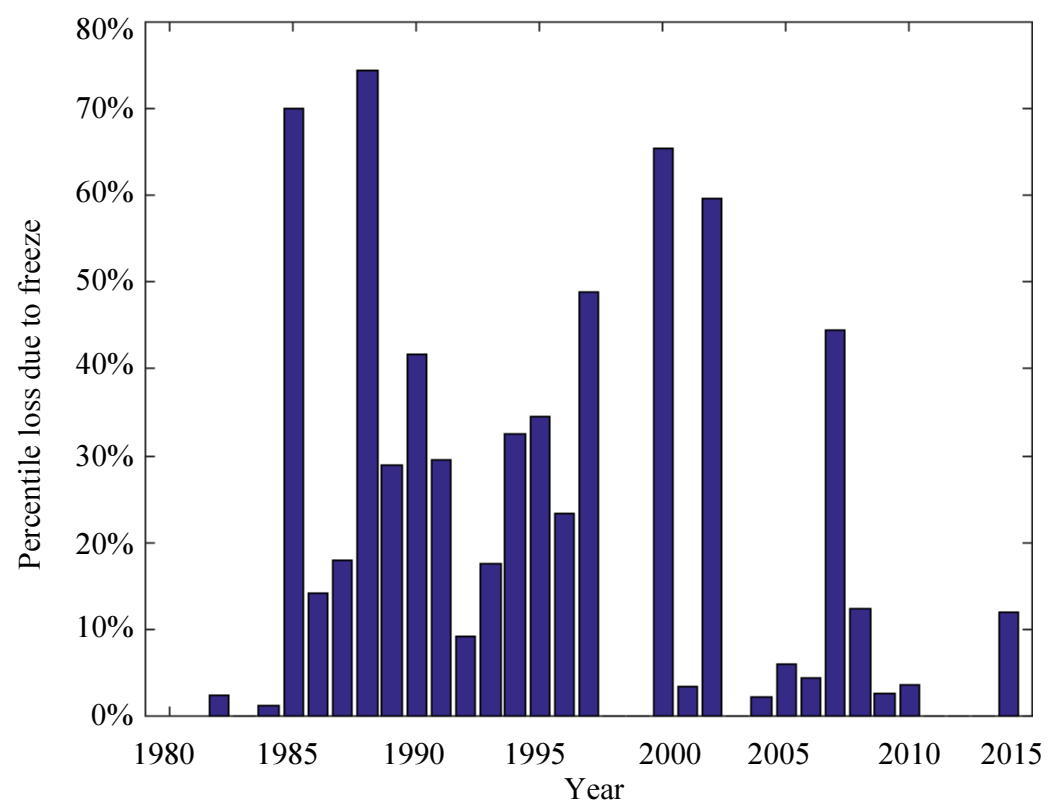

Fig. 2: Annual percentile loss for top five Missouri counties with highest amount of crop loss due to freeze (1979 to 2015)

Table 3: Missouri's top five freeze loss counties and years of maximum crop loss (1982-2015)

\begin{tabular}{|c|c|c|c|c|c|c|c|}
\hline \multicolumn{8}{|c|}{ Audrain County, Total Loss: $\$ 1,346,595$} \\
\hline Year & 1986 & 1988 & 1989 & 1990 & 1992 & 1995 & 1996 \\
\hline Crop Loss (USD) & 47,010 & 8,894 & 37,512 & 14,703 & 28,776 & 89,819 & $\mathbf{9 4 0 , 3 1 5}$ \\
\hline Year & 1997 & 2002 & 2007 & 2008 & 2009 & 2014 & \\
\hline Crop Loss (USD) & 7,006 & 5,840 & 137,701 & 712 & 7,984 & 20,323 & \\
\hline \multicolumn{8}{|c|}{ Vernon County, Total Loss: $\$ 1,524,733$} \\
\hline Year & 1986 & 1989 & 1991 & 1995 & 1996 & 2000 & \\
\hline Crop Loss (USD) & 2,121 & 10,427 & 1,836 & 23,477 & 86,720 & 711,982 & \\
\hline Year & 2001 & 2004 & 2005 & 2007 & 2010 & 2014 & \\
\hline Crop Loss (USD) & 1,843 & 3,860 & 2,795 & 664,217 & 5,637 & 9,818 & \\
\hline \multicolumn{8}{|c|}{ Lafayette County, Total Loss: $\$ 2,291,730$} \\
\hline Year & 1985 & 1986 & 1989 & 1990 & 1991 & 1992 & \\
\hline Crop Loss (USD) & 6,976 & 5,985 & 56,106 & 100,907 & 143,012 & 48,378 & \\
\hline Year & 1993 & 1994 & 1995 & 1996 & 1997 & 2001 & \\
\hline Crop Loss (USD) & 6,444 & 61,010 & 357,675 & 69,298 & 1,644 & 383 & \\
\hline Year & 2005 & 2006 & 2007 & 2008 & 2009 & 2014 & \\
\hline Crop Loss (USD) & 6,873 & 964 & $1, \mathbf{4 1 6 , 5 9 7}$ & 4,322 & 4,799 & 357 & \\
\hline \multicolumn{8}{|c|}{ Barton County, Total Loss: $\$ 2,596,593$} \\
\hline Year & 1984 & 1985 & 1987 & 1993 & 1994 & 1995 & \\
\hline Crop Loss (USD) & 2,914 & 67,800 & 1,053 & 42,886 & 3,400 & 823 & \\
\hline Year & 1996 & 2000 & 2001 & 2002 & 2007 & 2008 & \\
\hline Crop Loss (USD) & 55,786 & $1,019,166$ & 364 & 4,905 & $1,356,578$ & 40,918 & \\
\hline \multicolumn{8}{|c|}{ Dunklin County, Total Loss: $\$ 2,854,969$} \\
\hline Year & 1982 & 1984 & 1985 & 1986 & 1989 & 1990 & 1991 \\
\hline Crop Loss (USD) & 777 & 1,838 & $1,340,196$ & 33,813 & 115,496 & 150,071 & 7,364 \\
\hline Year & 1992 & 1993 & 1994 & 1996 & 2007 & 2014 & \\
\hline Crop Loss (USD) & 19,197 & 3,715 & 53,910 & 28,153 & $1,051,471$ & 48,968 & \\
\hline
\end{tabular}

Note: The numbers in bold face indicate the maximum loss and year in each county 


\section{Spatial Crop Loss Data Analysis}

From this analysis, it is observed that the freeze loss in the top five counties totals $\$ 10,614,620$ USD and total freeze loss for all counties amounts to $\$ 28,947,542$ USD. Therefore, the top five counties are responsible for $36.67 \%$ of the overall freeze loss in Missouri and thus these counties have a high percentage in the overall freeze loss. It appears freeze loss in Missouri is concentrated in certain areas. The counties responsible for $36.67 \%$ of Missouri's overall freeze risk are therefore considered more vulnerable to freeze events. These vulnerable counties include Dunklin, Barton, Lafayette, Vernon and Audrain as outlined in Table 3.

Table 4 represents the top five annual Missouri counties with highest amount of freeze event crop loss. Moreover, in 1983, 1987, 1999 and 2003 there have been less than five counties in Missouri with insurance claims for crop loss due to freeze. Hence, in these years there have been no significant crop loss due to spring freeze. Review of the annual reported top freeze loss counties for Missouri can help identify larger vulnerable freeze regions within the state.
Figure 3 is used to visualize the top five Missouri counties with the highest annual crop loss due to springtime freeze and how the locations of highest loss counties may have changed over time. The central, southeast and western counties are identified as highrisk regions for freeze events. By contrast, other state counties have never ranked as a top five loss county during the past thirty-four years. Figure 3 places an emphasis on the spatial diversity and patterns for the top five freeze loss counties. The illustrated areas of Central Missouri, Southeast Missouri and Western Missouri are identified as at risk for spring freeze events, including being especially susceptible in sustaining associated agricultural losses.

Table 5 represents the number of affected Missouri counties per year due to freeze from 1982 to 2015 . From Table 5, the most significant years in terms of number of affected counties were 1985, 1992, 1995, 1996, 2005 and 2007. The respective number of affected counties in these years are 36, 53, 51, 68, 38 and 77. Apart from 2005, these freeze years also directly correspond to the largest reported freeze event losses in USD, illustrated in Table 2.

Table 4: Annual top five Missouri counties with highest freeze event crop loss (1982-2015)

\begin{tabular}{|c|c|c|c|c|c|}
\hline 1982 & Mississippi & Ripley & Franklin & New Madrid & Callaway \\
\hline 1983 & Platte & Butler & Franklin & $\mathrm{X}$ & X \\
\hline 1984 & Howard & Stoddard & Mercer & Pemiscot & Lewis \\
\hline 1985 & Dunklin & Henry & Linn & Chariton & Barton \\
\hline 1986 & Moniteau & Bates & Cooper & Audrain & Pettis \\
\hline 1987 & Bates & Barton & Gentry & $\mathrm{X}$ & $\mathrm{X}$ \\
\hline 1988 & Audrain & Mercer & Monroe & Shelby & Knox \\
\hline 1989 & Montgomery & Dunkin & Lafayette & Warren & Audrain \\
\hline 1990 & Dunklin & Lafayette & Scott & Monroe & Jackson \\
\hline 1991 & Lafayette & Saline & Sullivan & Howard & Pemiscot \\
\hline 1992 & Pemiscot & Marion & Callaway & Montgomery & Lafayette \\
\hline 1993 & St. Louis & Barton & Jasper & Carroll & Lafayette \\
\hline 1994 & Lafayette & Dunklin & Howard & Carroll & Cooper \\
\hline 1995 & Lafayette & Lewis & Audrain & Cass & Callaway \\
\hline 1996 & Audrain & Callaway & Cooper & Montgomery & Saline \\
\hline 1997 & Audrain & Franklin & Adair & Lafayette & Warren \\
\hline 1998 & New Madrid & Mississippi & Scott & Pettis & Andrew \\
\hline 1999 & Carrol & $\mathrm{X}$ & X & $\mathrm{X}$ & $\mathrm{X}$ \\
\hline 2000 & Barton & Vernon & Bates & Jasper & Scott \\
\hline 2001 & Jasper & Pemiscot & Chariton & Cass & \\
\hline \multicolumn{6}{|l|}{ Lawrence } \\
\hline 2002 & Audrain & Barton & Clinton & Shelby & Moniteau \\
\hline 2003 & Cooper & Pettis & $\mathrm{X}$ & $\mathrm{X}$ & $\mathrm{X}$ \\
\hline 2004 & Pemiscot & Pettis & Lewis & Johnson & \\
\hline \multicolumn{6}{|l|}{ Randolph } \\
\hline 2005 & Ray & New Madrid & Johnson & Andrew & Scotland \\
\hline 2006 & Dade & Gentry & Moniteau & Saline & Cass \\
\hline 2007 & Lafayette & Barton & Dunklin & Vernon & Jasper \\
\hline 2008 & Mercer & Livingston & Jackson & Barton & Cooper \\
\hline 2009 & De Kalb & Knox & Mercer & Scotland & Clark \\
\hline 2010 & Pettis & Bates & Cooper & Henry & Johnson \\
\hline 2011 & Henry & Clark & Knox & Howard & Pettis \\
\hline 2012 & Warren & Lincoln & Saline & Moniteau & Carroll \\
\hline 2013 & Jasper & Randolph & New Madrid & Henry & \\
\hline \multicolumn{6}{|l|}{ Gasconade } \\
\hline 2014 & Lawrence & Grundy & Linn & Lincoln & Dunklin \\
\hline 2015 & Livingston & Bates & Montgomery & Callaway & Mercer \\
\hline
\end{tabular}

Note: ' $X$ ' is used to indicate that less than 5 counties were affected in those specific years 
Table 5: Number of Missouri counties (NC) affected per year due to freeze (1982-2015)

\begin{tabular}{lrrr}
\hline Year & NC & Year & NC \\
\hline 1982 & 10 & 1999 & 1 \\
1983 & 3 & 2000 & 13 \\
1984 & 26 & 2001 & 25 \\
1985 & 36 & 2002 & 8 \\
1986 & 26 & 2003 & 2 \\
1987 & 3 & 2004 & 14 \\
1988 & 6 & 2005 & 38 \\
1989 & 31 & 2006 & 7 \\
1990 & 19 & 2007 & 77 \\
1991 & 17 & 2008 & 21 \\
1992 & 53 & 2009 & 24 \\
1993 & 11 & 2010 & 16 \\
1994 & 13 & 2011 & 7 \\
1995 & 51 & 2012 & 5 \\
1996 & 68 & 2013 & 11 \\
1997 & 10 & 2014 & 35 \\
1998 & 8 & 2015 & 11 \\
\hline
\end{tabular}

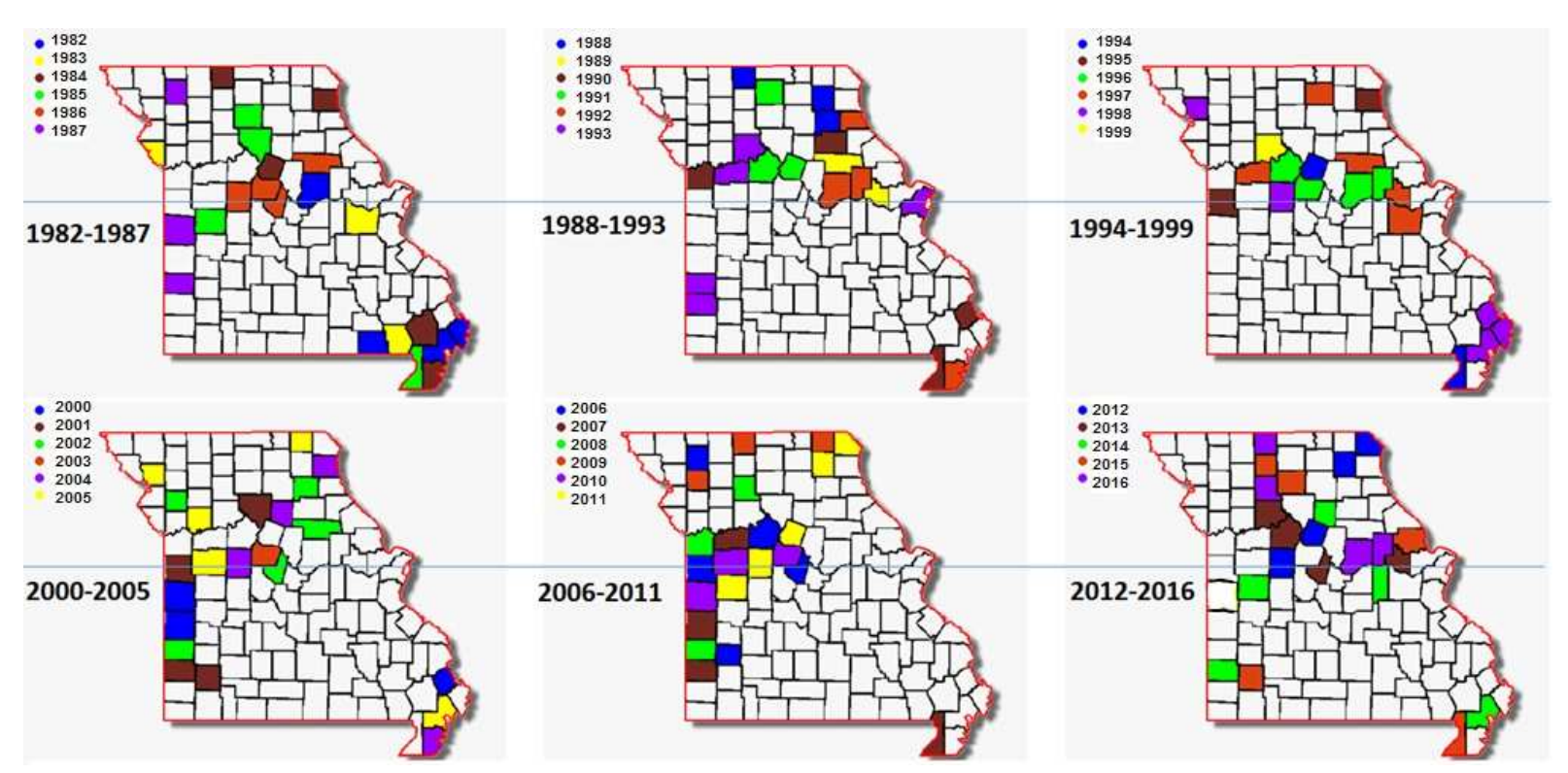

Fig. 3: Mapping of vulnerable Missouri freeze regions. Illustrated by annual top five Missouri crop loss counties 1982-2015. Note: Horizontal lines are provided for better visualization of affected counties

\section{Lafayette County Missouri Analysis}

Lafayette County appears to be affected by spring freeze events more frequently than other Missouri Counties examined from 1982-2015. Figure 4 shows that freeze effects had an adverse impact upon total crop loss for Lafayette County during 1990-1992, 1994-1996 and 2007. Specifically, the corresponding insurance amounts paid due to spring freeze exceeded $\$ 100,000$ in years 1990, 1991, 1995 and 2007. Most other years have little to no crop loss, as freeze events do not always occur during a vital stage of crop development. As anticipated, the four most damaging freezes in Lafayette County are associated with spring freeze events which occur in the final days of March into the first week of April.
In addition, the four freeze years of 1990, 1991, 1995 and 2007 constitute eighty-eight percent of all total Lafayette County crop losses during thirty-four-year period. It is of note, that all four of these freeze years also constitute late spring freeze events. A factor of a damaging spring freeze, is the freeze event itself. All four marked years of Lafayette County's significant loss correspond to a freeze event. These four freeze events also occurred at a time within the final week of March and initial 10 days of April, in which, temperatures fell below $-4.44^{\circ} \mathrm{C}$, resulting in their categorization as a severe freeze event (Walter et al. 1988, section: C, page: I4). It is possible to conclude that freeze events cause agricultural damage and a narrow seasonal window 
emerges in late spring where a freeze event can cause devastating crop loss. The results for Lafayette County include the following:

i. For 1982-2015, Lafayette appeared nine times within yearly top five counties in the amount of crop loss, accounting for about $28 \%$ of the thirty-fouryear span examined

ii. Lafayette ranks third among Missouri counties for total amount of crop loss reported during 1982-2015

iii. Lafayette County is affected by freeze events for eighteen years which is maximum among the top five counties with the highest crop loss

One way to lend additional credence to the idea of a small window for increased crop loss risk is a correlation analysis (Hansen et al., 1998). By weighting the severity of the freeze on a day using a standard of light, mild (between 0 to $-1.66^{\circ} \mathrm{C}$ ), moderate (between $-1.66^{\circ} \mathrm{C}$ to $-4.44^{\circ} \mathrm{C}$ ) and severe (below $-4.44^{\circ} \mathrm{C}$ ) freezes summed together from late March through early April are compared against crop loss for each year across the 34-year data set. Correlation analysis between the crop loss data set and a weighted minimum daily temperature (late March through early April) gives a correlation of 0.57 .

The second factor or sign of damaging freeze events, which all four crop loss events also have in common, is a warm period prior to the freeze event (Wolf, 2007). When examining the temperatures leading up to the freeze, it is apparent that temperature is significantly higher than normal across much of the preceding month. This is evident in Lafayette County as well. As shown in Fig. 5, in all years with significant crop loss due to freeze, there has been an unusual warm period before the severe freeze event in late March or early April. Moreover, in Table 6 it is observed that the length of the warm period prior to the freeze event is linked to a corresponding increase in reported crop loss.

Table 6: Lafayette County's highest freeze loss years with accompanying warm-cold temperature periods

\begin{tabular}{lllll}
\hline Year & 1990 & 1991 & 1995 & 2007 \\
\hline Recorded dates of warm period & March 5th-22nd & March 9th-27th & March 10th-29th & March 5th-April 3rd \\
Period's number of warm days & 18 & 19 & 20 & 30 \\
Sum average daily temp. $\left({ }^{\circ} \mathrm{C}\right)$ & $130.05^{\circ} \mathrm{C}$ & $113.35^{\circ} \mathrm{C}$ & $145.63^{\circ} \mathrm{C}$ & $264.62^{\circ} \mathrm{C}$ \\
Recorded dates of cold period & March 23rd-27th & March 28th-30th & March 30th -31st & April 4th-9th \\
Period's number of cold days & 5 & 3 & 2 & 6 \\
Sum average daily temp. $\left({ }^{\circ} \mathrm{C}\right)$ & $-28.19^{\circ} \mathrm{C}$ & $-6.04^{\circ} \mathrm{C}$ & $-4.49^{\circ} \mathrm{C}$ & $-28.02^{\circ} \mathrm{C}$ \\
Recorded crop loss (USD) & $\$ 100,907$ & $\$ 143,012$ & $\$ 357,675$ & $\$ 1,416,597$
\end{tabular}

Note: Temperature rows represent a sum of the average daily temperatures in Celsius. Warm patterns seem to demonstrate a stronger influence on the crop loss; when compared to the number of total days and degree sum of average daily temperatures (Celsius)

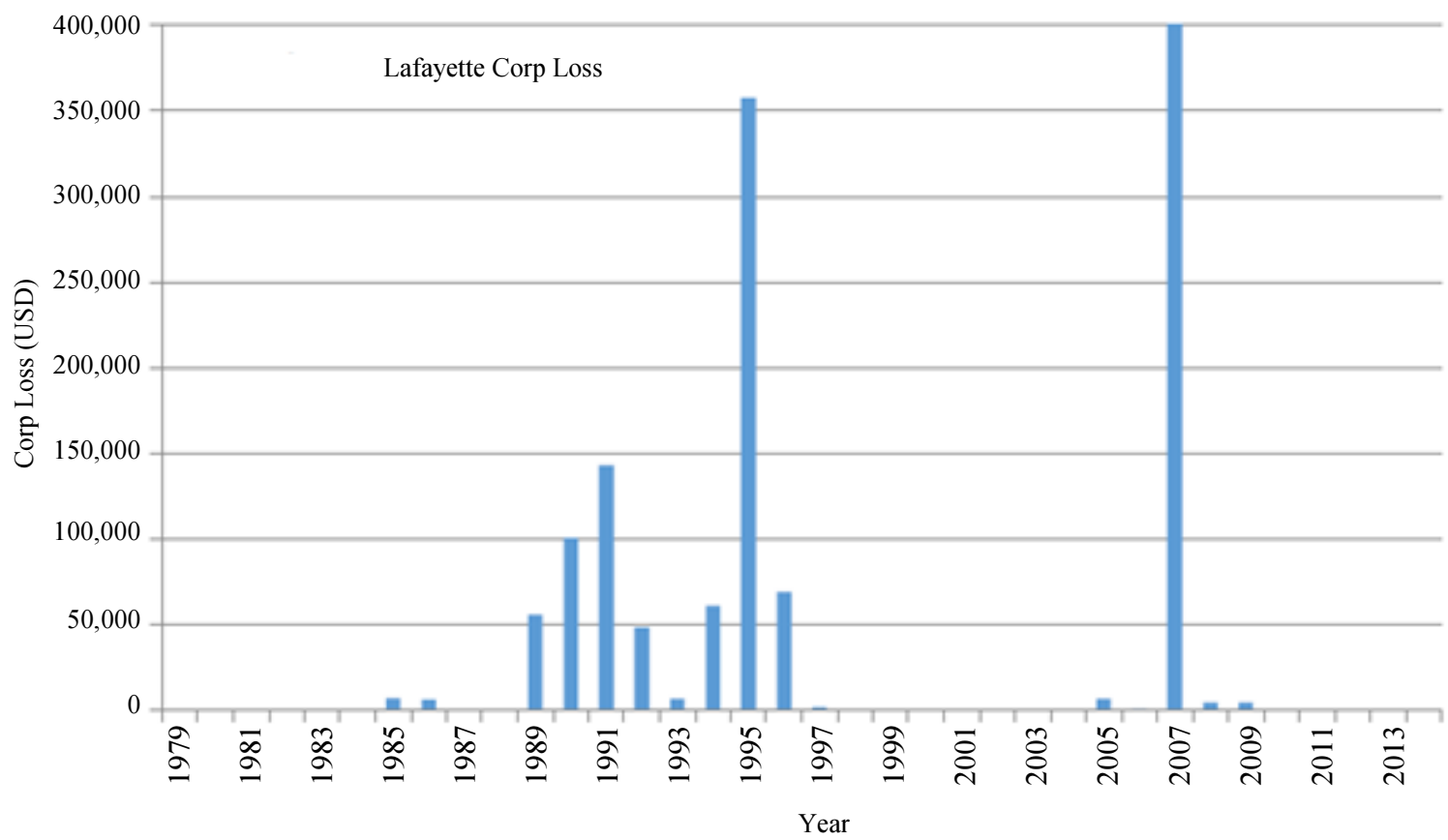

Fig. 4: Crop loss due to freeze per year in Lafayette County, Missouri with dollar amount adjusted to the year $2016 . * 2007$ is truncated due to the large crop loss value 


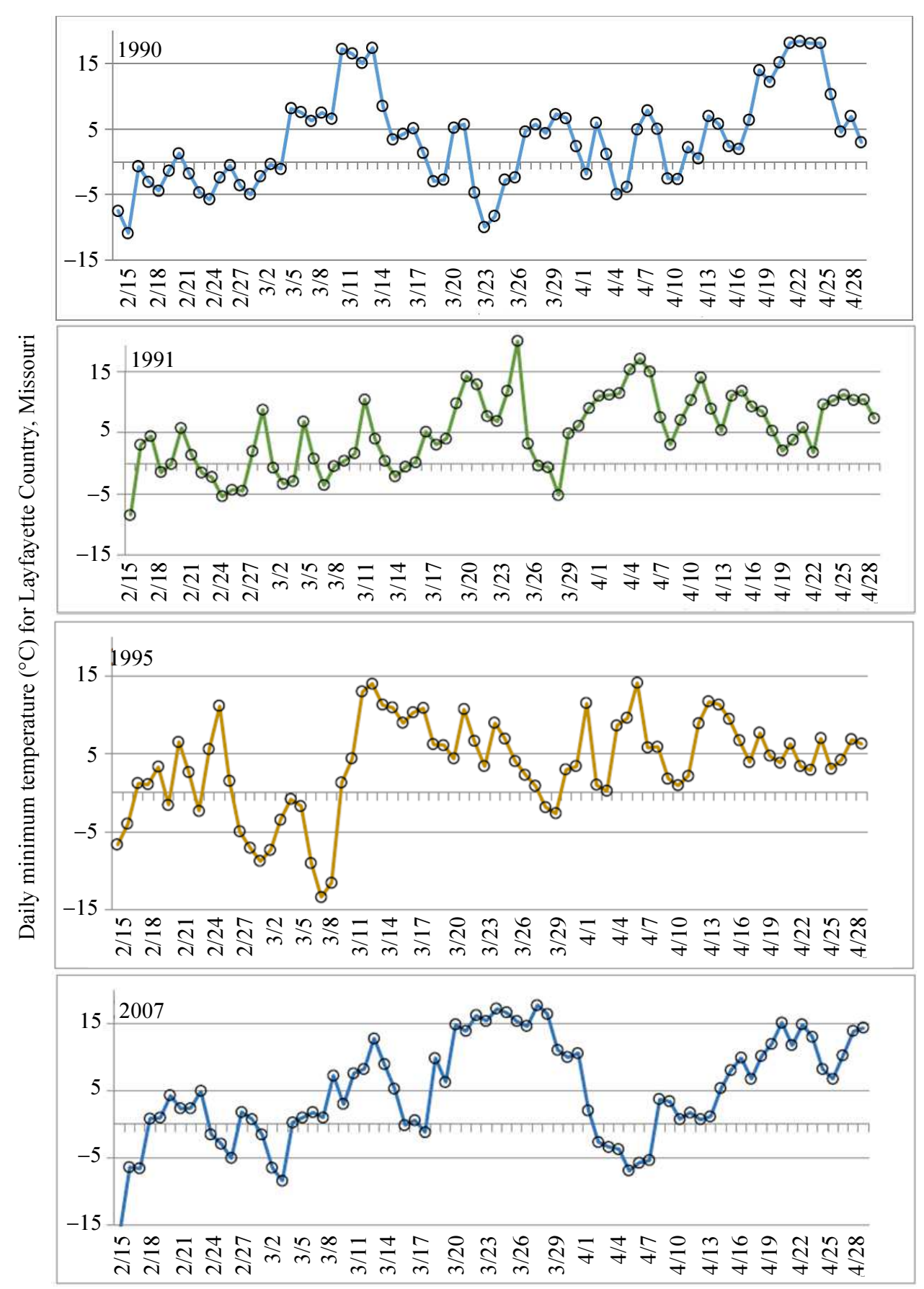

Month and day of recorded minimum temperatures

Fig. 5: In 1990, 1991, 1995 and 2007, the crop loss in Lafayette County is much higher than in other years. The patterns of warmcold temperature fluctuations have frequently occurred in these years and the crop loss is significantly correlated with these patterns (correlation $r=0.57$ )

\section{Discussion}

In the present work, climate and crop loss data for Missouri was analyzed from 1982 to 2015. Data analysis confirms the Easter freeze of 2007 was especially devastating due to unseasonably warm March temperatures, followed in combination by both a radiational freeze and an advective freeze.

Further, regions in Missouri with high risk of crop loss due to spring freeze events were identified. There is 
a need to pay special attention towards counties in these regions to cut down figure losses as a result of spring freeze events. The central, southeastern and western regions of Missouri are identified as most vulnerable to spring freeze event occurrence. The top-ranking Missouri counties for freeze crop loss are Audrain, Barton, Dunklin, Lafayette and Vernon. During this period, Lafayette County appears nine times in the top five counties for total crop loss, accounting for approximately $28 \%$ of the thirty-four years examined. Further analysis of Lafayette County revealed a total of eighteen years impacted by freeze events, representing a maximum among top five counties with highest crop loss. The years of 1990, 1991, 1995 and 2007 constitute eighty-eight percent of Lafayette County's total freeze loss during 1982-2015. These years include an unusual period of warm temperatures.

In Lafayette County, the length of the warm period prior to a freeze event was observed to impact the corresponding crop losses. For instance, 1990 and 2007 are similar in their respective number of cold days and temperature sum. However, of these two years, 2007 bears a marked warm period extending from 18 to 30 days in length, as well as a drastic increase in total crop losses reported from $\$ 100,907$ in 1990 to $\$ 1,416,597$ for 2007. In observing a plant's response to warm period durations, a direct relationship can be inferred from the length of a warm period and potential freeze damage. The longer the duration of a warm period the more likely a plant is to have undergone de-acclimation or be in a vulnerable growth phase such as bud formation. Spring freeze events coincide with the initial growth periods of many food crops, consequently these events produce both susceptibility and occurrence concerns for agricultural production. If early warm spring temperatures are succeeded by one or more freeze events, the resulting freeze is often extremely damaging to agricultural crops.

The analysis also revealed patterns of occurrence during freeze crop losses. This emerged from the insurance claims filed. Over the thirty-four-year span of the dataset, insurance claims for freeze loss are distributed unevenly. Many years amount to little loss, while others result in steep spikes in reported amounts of freeze loss and corresponding insurance claims. The years that experienced the greatest amount of crop losses corresponded to the years of 1985, 1996 and 2007. 3 The research also identified a second interesting pattern within Missouri's most severe spring freeze years and the maximums in reported agricultural losses. Reported losses double from the 1985 to 1996 spring freezes and appear to double again for the 1996 to 2007 events.

Future considerations include examination of other significant freezes outside of Missouri or the 1982-2015 timeline to determine if they are also affected by a combination of both advective and radiational freeze type events. Further review and analysis of significant freeze events produced by singular freeze events that lack a preceding warm period can perhaps identify and aid in predicting the event's severity.

Understanding the compounding effect of a warm March followed by a freeze can allow farmers to properly plan for an increase of significant freeze damage for those years. Additional research could help define a freeze-related agro-climate metric, which could then be modeled to determine how the frequency of the metric changes from a past state to a future state. This metric could prove helpful to the farming community, as it could offer useful guidance to farmers on when they should plant certain crops locally and regionally. This would certainly help to mitigate the negative impacts for future spring freeze events, such that it could improve agricultural awareness regarding optimal plantation and seeding times.

\section{Acknowledgment}

We would like to thank and acknowledge the following for their support of this work:

1. University of Missouri-Kansas City Faculty for Excellence Program, FFE NV KDW3

2. This material is based upon work supported by the National Science Foundation under Award Number IIA-1355406. Any opinions, findings, and conclusions or recommendations expressed in this material are those of the author(s) and do not necessarily reflect the views of the National Science Foundation.

\section{Author's Contributions}

Mirza Mohd Shahriar Maswood: Crop Loss analysis, writing sections, and research plan.

Ali Koleiny: Writing and editing sections of paper.

Scott Nickell: Data Analysis, acquisition, and paper writing.

Laura Wymer: Writing, elaboration of plant biological processes, and data analysis.

Ronald Morris: Data acquisition and analysis.

Majid Bani-Yaghoub: Design of the study and supervising data analysis.

Jimmy Adegoke: Contributed to the design of the study, reviewed the results of the analysis and contributed to the writing of the manuscript.

\section{Ethics}

The corresponding author confirms that the coauthors have read and approved the manuscript and there are no ethical issues. 


\section{References}

Brotak, E., 2014. The big freeze: Frost's costly impact on agriculture. Weatherwise. 67: 30-35. DOI: $10.1080 / 00431672.2014 .859937$

Burke, M.J., L.V. Gusta, H.A. Quamme, C.J. Weiser and P.H. Li, 1976. Freezing and injury in plants. Ann. Rev. Plant Physiol., 27: 507-528. DOI: 10.1146/annurev.pp.27.060176.002451

Daly, C., M.P. Widrlechner, M.D. Halbleib, J.I. Smith and W.P. Gibson, 2012. Development of a new USDA plant hardiness zone map for the United States. J. Applied Meteorol. Climatol., 51: 242-264. DOI: $10.1175 / 2010 J A M C 2536.1$

Ehlenfeldt, M.K., L.J. Rowland, E.L. Ogden and B.T. Vinyard, 2012. Cold-hardiness, acclimation and deacclimation among diverse blueberry genotypes. J. Am. Society Horticultural Sci., 137: 31-37.

Gu, L., P.J. Hanson, W. Mac Post, D.P. Kaiser and B. Yang et al., 2008. The 2007 eastern US spring freeze: Increased cold damage in a warming world. BioScience, 58: 253-262. DOI: 10.1641/B580311

Hansen, J.W., A.W. Hodges and J.W. Jones, 1998. ENSO influences on agriculture in the southeastern United States. J. Climate, 11: 404-411. DOI: 10.1175/15200442(1998)011<0404:EIOAIT>2.0.CO;2

Laforge, M.P., N.L. Michel and R.K. Brook, 2017. Spatio-temporal trends in crop damage inform recent climate-mediated expansion of a large boreal herbivore into an agro-ecosystem. Sci. Reports, 7: 1-11. DOI: 10.1038/s41598-017-15438-x

Li, P.H. and A. Sakai, 1982. Plant Cold Hardiness and Freezing Stress: Mechanisms and Crop Implications. 1st Edn., Academic Press, New York, London, ISBN-10: 0124476023, pp: 694.

McMechan, J. and R. Elmore, 2016. Nebraska corn: Risk of freeze damage if you plant too early. AGFAX.

MDA, 2014. Grants awarded to grow demand for Missouri specialty crops. Missouri Department of Agriculture.

Monsanto, 2017. Biotechnology and GMOs.
NOAANCEI, 2017. Billion-dollar weather and climate disasters: Table of events. NOAA National Centers for Environmental Information (NCEI), U.S.

Ozaki, V.A., S.K. Ghosh, B.K. Goodwin and R. Shirota, 2008. Spatio-temporal modeling of agricultural yield data with an application to pricing crop insurance contracts. Am. J. Agric. Eco., 90: 951-961. DOI: $10.1111 /$ j.1467-8276.2008.01153.x

Regan, R., 2012. Helping plants survive the cold. Digger.

Saha, S. and Coauthors, 2010. Climate Forecast System Reanalysis (CFSR). National Centers for Environmental Prediction (NCEP).

Sesnie, S.E., B. Tellman, D. Wrathall, K. McSweeney and E. Nielsen et al., 2017. A spatio-temporal analysis of forest loss related to cocaine trafficking in Central America. Environ. Res. Lett., 12: 1-14. DOI: $10.1088 / 1748-9326 /$ aa6fff

Snyder, R.L., 2000. Principles of frost protection. University of California-Davis, USA.

Striegler, R.K., A. Allen and E. Bergmeier 2007. The easter freeze of 2007: Extent of damage and strategies for managing freeze-injured vineyards. University of Missouri-Columbia Grape and Wine Institute, USA.

Taiz, L. and E, Zeiger, 2007. Plant Cells. In: Plant Physiology, Taiz, L. and E, Zeiger (Eds.), Sinauer Associated, Inc.

USDA-RMA, 2016. Cause of loss historical data files. The United States Department of Agriculture Risk Management Agency.

Warmund, M.R., P. Guinan and G. Fernandez, 2008. Temperatures and cold damage to small fruit crops across the eastern United States associated with the April 2007 freeze. HortScience, 43: 1643-1647.

Wolf, R., 2007. The Easter freeze of April 2007: A climatological perspective and assessment of impacts and services. NOAA/USDA Technical Report 2008-01, pp: 56. 